Osteoporos Int. Author manuscript; available in PMC 2016 November 10.

Published in final edited form as:

Osteoporos Int. 2011 March ; 22(3): 967-982. doi:10.1007/s00198-010-1424-x.

\title{
Cost-effectiveness of Denosumab for the treatment of postmenopausal osteoporosis
}

\author{
B. Jönsson, \\ Stockholm School of Economics, Box 6501, SE 11383 Stockholm, Sweden \\ O. Ström, \\ i3 Innovus, Stockholm, Sweden, Department of Learning, Informatics, Management, and Ethics, \\ Medical Management Centre, Karolinska Institutet, Stockholm, Sweden
}

J. A. Eisman, UNSW, Garvan Institute of Medical Research, St Vincent's Hospital, Sydney, Australia

\author{
A. Papaioannou, \\ McMaster University, Hamilton, ON, Canada
}

E. S. Siris, Columbia University, New York, NY, USA

A. Tosteson, and Dartmouth Medical School, Lebanon, NH, USA

\author{
J. A. Kanis \\ WHO Collaborating Centre, University of Sheffield, Sheffield, UK
}

\section{Abstract}

Summary-Denosumab is an injectable drug that reduces the risk of fractures. The objective was to estimate the cost-effectiveness of denosumab in a Swedish setting, also accounting for poor adherence to treatment. Denosumab is cost-effective, particularly for patients at high risk of fracture and low adherence to oral treatments.

Introduction-Denosumab is a novel biologic agent developed for the treatment of osteoporosis and osteoporotic fractures that has been shown to reduce the risk of fractures in a phase III trial. The objective of this study was to estimate the cost-effectiveness of denosumab from a societal perspective compared with generic alendronate, branded risedronate, strontium ranelate, and no treatment in a Swedish setting.

Methods-A Markov cohort model was used to estimate the cost-effectiveness of denosumab given for up to 5 years to a typical Swedish patient population (women aged 71 years, T-score= $-2.5 \mathrm{SD}$ and a prevalence of morphometric vertebral fractures of $34 \%)$. The model included treatment persistence and residual effect after discontinuation assumed to be equal to the time on

Correspondence to: B. Jönsson.

Conflicts of interest Sponsored by Amgen. 
treatment. Persistence with the comparator treatments and with denosumab was derived from prescription data and a persistence study, respectively.

Results-The base-case incremental cost-effectiveness ratios were estimated at $€ 27,000$, $€ 12,000, € 5,000$, and $€ 14,000$, for denosumab compared with generic alendronate, risedronate, strontium ranelate, and no treatment, respectively. Suboptimal persistence had the greatest impact in the comparison with generic alendronate, where the difference in drug cost was large.

Conclusion-Improving persistence with osteoporosis treatment impacts positively on costeffectiveness with a larger number of fractures avoided in the population targeted for treatment. Denosumab is a cost-effective alternative to oral osteoporosis treatments, particularly for patients at high risk of fracture and low expected adherence to oral treatments.

\section{Keywords}

Adherence; Compliance; Fracture; Model; Persistence; Sweden

\section{Introduction}

The clinical consequences of osteoporosis are mainly the increased incidence of fractures and their associated morbidity and premature mortality. Beside the negative impact on the quality of life of the individual, osteoporosis is a costly disease for society. The societal costs associated with the disease are also expected to increase in the future, partly due to changes in demography and improved life expectancy, and in many countries due to an increase in age-specific incidence of fractures. In 1990, the number of osteoporotic fractures in Europe was estimated to be 2.7 million, with a direct cost of $€ 36$ billion, of which $€ 24.3$ billion were accounted for by hip fractures. Costs are expected to rise to $€ 76.8$ billion by the year 2050 [1] because of the increasing proportion of elderly in the population.

The importance of developing treatments that reduce the risk of fracture is evident, both from an individual and a societal perspective and a number of agents are available that have been shown in randomized controlled trials (RCTs) to decrease the risk of vertebral and, in some instances, non-vertebral fracture [2]. Denosumab is a novel biologic agent for the treatment of osteoporosis in post-menopausal women at increased risk of fractures. It is a fully human monoclonal antibody that specifically, and with high affinity, binds and neutralizes RANKL, a key mediator of the resorption phase of bone remodeling [3]. In a 3year randomized phase III trial that included postmen-opausal women with osteoporosis, denosumab (60 mg subcutaneously every 6 months) significantly reduced the risk of osteoporotic fractures, including fractures of the vertebra, non-vertebral, and hip [4].

Adherence to medication is low in osteoporosis and as problematic, if not worse, than in other chronic diseases [5, 6]. An attractive feature of the 6-monthly regimen with denosumab is that adherence may be improved compared to alternative treatments, thereby improving effectiveness in clinical practice, resulting in more fractures avoided. In addition, improving adherence can improve cost-effectiveness, although the effect size is context specific and modulated by factors such as the comparative efficacy of treatment, drug price, and fracture risk [7]. 
Where resources within the health-care sector are scarce, it is important to conduct health economic evaluations of new treatment opportunities in order to determine priorities and thereby optimize health benefits for society. The objectives of this study were to undertake a health economic analysis of denosumab that incorporated adherence, and to estimate the cost-effectiveness of denosumab from a societal perspective compared with generic alendronate, branded risedronate, strontium ranelate, and to no treatment in a Swedish setting.

\section{Methods}

\section{Health economic model}

A Markov cohort model was used to estimate the cost-effectiveness of osteoporosis interventions (Fig. 1). The available transitions were similar to those previously published [8-10], with the addition of "other fractures", which was a composite health state consisting of pelvis, rib, humerus, tibia, fibula, clavicle, scapula, sternum, and other femoral fractures. The model used a 6-month-cycle length and the cohort was followed from the age of treatment initiation until death, or an age of 100 years.

The model consists of eight health states. All patients begin in the well health state. In each cycle, a patient has a probability of sustaining a fracture, remaining healthy or dying. After 6 months in any fracture state, the patient has a risk of sustaining a new fracture or dying. After 12 months, the patient moves to the corresponding post-fracture state if no additional event occurs. The patient will automatically remain in the post-fracture state (shown as a circular arrow) if she does not die or sustain a new fracture. The cohort framework allows no memory of an individual's disease history and transitions from post-hip to fractures other than a new hip fracture are therefore prohibited. For example, a wrist fracture after a hip fracture could otherwise appear to improve a patient's long-term health. Patients in postvertebral can only transit to hip or vertebral states. Costs, utilities, and mortality in each cycle were allocated according to the distribution over the health states.

The model was validated by successfully reproducing general population fracture risk data. The persistence framework also yielded very similar effect modifications, absolute fracture rates, and quality-adjusted life year (QALY) gains as reported in a previously published adherence model [7] when, as far as possible, the same settings and data were used.

\section{Patient population}

The base-case population was selected to be similar to the average postmenopausal woman that would start treatment for osteoporosis in Sweden. A recent Swedish prescription study reported that the mean age of patients starting osteoporosis treatment was 71 years [11]. The WHO definition of osteoporosis, with a T-score at the femoral neck at or below $-2.5 \mathrm{SD}$ [12], was used to describe the average patient which approximates the risk where treatment is recommended under the Swedish guidelines [13]. The approach to define the average treated patient to have a T-score at or below $-2.5 \mathrm{SD}$ was chosen because the average patient is unlikely to have a bone mass density (BMD) exactly at $-2.5 \mathrm{SD}$, but rather the average Tscore within the range below the threshold. 
The proportion of the female population with osteoporosis that has a prevalent morphometric vertebral fracture is not known and was therefore simulated from its incidence in the European Prospective Osteoporosis Study which examined a normal population [14] adjusted to reflect the northern European setting, post-fracture mortality (relative risk $(\mathrm{RR})=2.3)$ [15], and the lower BMD in an osteoporotic population. The prevalence of morphometric vertebral fracture in the base-case population was estimated at $34 \%$. The estimated annual hip and clinical vertebral fracture incidences at model entry in this population were 11.7 and 18.9 fractures per 1,000 patients. Sensitivity analyses were also performed for other combinations of age, T-score, and prevalence of morphometric fracture.

\section{Treatment and efficacy}

The study evaluated treatments that were intended to last for 5 years. Antifracture efficacies for alendronate, risedronate, and strontium ranelate (Table 1) were taken from a recent metaanalysis [16]. Efficacy for non-vertebral fractures was used for "other fractures" and also for wrist fracture, where specific estimates for wrist were not available. Point estimates that were not statistically significant were included. The efficacy of denosumab was taken from the Fracture Reduction Evaluation of Denosumab in Osteoporosis Every 6 Months (FREEDOM) study [4], which was a double-blind trial with 7,808 patients randomized to either denosumab or placebo (all patients received calcium and vitamin D supplementation). The mean age and femoral neck T-score of the trial population was 72.3 years and -2.16 SD, respectively. Inclusion of gastrointestinal adverse events associated with alendronate and risedronate treatment [17] was tested in sensitivity analysis using assumptions previously described [18]. Women who experienced bisphosphonate-related side effects were assumed to have $91 \%$ of the utility of women who do not have such side effects. This was applied to $2.35 \%$ of women in the first treatment month and $0.35 \%$ of women thereafter. Strontium ranelate has been shown to be safe and well tolerated during an 8-year follow-up [19], and no side effects were therefore assumed in the analysis. The FREEDOM study indicated that skin infections, including cellulitis, were reported more frequently with denosumab $(0.3 \%$ over 3 years). This was estimated to have a negligible effect on the results and was therefore omitted from the analysis.

\section{Adherence}

A previously published adherence modeling framework was used to model adherence [7]. Adherence encompassed persistence (time on treatment) and compliance, defined as medication possession ratio (MPR) while still persistent. MPR was the number of days with available medication supply divided by all days during the treatment period.

Persistence inputs for the comparator treatments were based on a recent Swedish study of all filled prescriptions for alendronate, risedronate, raloxifene, and strontium ranelate in 53,336 treatment-naïve patients (excluding secondary osteoporosis) [11]. Of the prescriptions filled, $77 \%$ and $20 \%$ were for alendronate and risedronate, respectively. Switching between treatments (6\% of patients) was allowed to avoid underestimating true persistence. Proportions of women still on any treatment at 6, 12, 18, 24, 30, and 36 months were 63\%, $47 \%, 39 \%, 30 \%, 24 \%$, and $17 \%$, respectively. Patients were assumed to be at risk of dropping out during the first 3 years and thereafter remain persistent for the intended 
treatment duration. Even though there may be observable differences between the individual treatments, they were combined into one group since non-persistence otherwise may be caused by a deliberate switch to another alternative.

In the same study [11], MPR was estimated at 95\%, which is higher than reported in other studies [20]. Refill compliance was therefore disregarded in the present health economic analysis. For patients receiving treatment, we thus assumed the same compliance as reported in the clinical trials, from which the data on efficacy were taken.

No prescription data were available for denosumab and persistence was estimated from the Denosumab Adherence Preference Satisfaction study (DAPS), which is an ongoing 2-year multi-center, randomized, cross-over, and open-label study in 250 patients to evaluate the adherence, preference, and satisfaction of 6-monthly denosumab and weekly alendronate in postmenopausal women with low bone mineral density [21]. In the interim analysis at 1 year, discontinuation rates were $10.3 \%$ and $20.2 \%$ for denosumab and alendronate, respectively (relative risk $0.54 ; p=0.0492$ ). The predicted, time-specific non-persistence with denosumab in the base case was estimated by multiplying the time-specific dropout incidence obtained from Swedish prescriptions [11] by 0.54 during the treatment duration (i.e., improved persistence was assumed for 36 months). Estimated proportions of patients on treatment with denosumab at $6,12,18,24,30$, and 36 months were $80 \%, 69 \%, 60 \%$, $54 \%, 48 \%$, and $40 \%$, respectively. In a sensitivity analysis, we varied the persistence with denosumab while keeping the adherence rates for the other agents constant (i.e., as described above).

\section{Persistence and offset time}

Osteoporosis models commonly assume a 5-year treatment duration followed by a period of 5 years (offset time) where the fracture risk linearly returns to the risk of an untreated population $[8,9,22]$. This offset assumption is reasonable if patients stay on treatment over long periods, as in phase III studies (i.e., 3 years or more), but may not be appropriate in a model that explicitly incorporates discontinuation of treatment. For example, a 5-year offset in a patient that discontinued treatment after 1 year would be given 5 years of "free" effect during the offset period. For this reason, offset time was assumed to equal the time on treatment [7] and was consequently shorter for patients who discontinued before the end of the intended treatment duration. The intended exposure to treatment was set to 5 years and the maximum offset time was set at 5 years for all treatments. A patient injected with denosumab is automatically persistent for 6 months whilst a patient on oral bisphosphonates will discontinue sometime during the 6-month period. Treatment effect was therefore reduced by half in the dropout cycle for orally administered medications (i.e., 3 months of treatment effect was removed).

\section{Assessing fracture risk}

The RR of fracture of patient groups compared to the general population risk was calculated from age, BMD, and the prevalence of vertebral fractures by methods previously described $[8,23,24]$. The risk contribution from prior vertebral fracture was re-estimated for each cycle to account for age-dependent changes in the prevalence of vertebral fracture in the 
general population. RR of hip fractures was also adjusted over time to accommodate the decreasing gradient of fracture risk per standard deviation of BMD with age [25]. RRs at or below a certain femoral neck T-score were calculated by dividing the distribution below a given T-score into $0.1 \mathrm{SD}$ wide slices, and summarizing the RR. This method was applied because RR increases exponentially with decreasing BMD. The RRs at model entry of hip, vertebral, wrist, and other fractures were estimated at 2.33, 2.66, 1.46, and 1.71 for the basecase population. Thus these RRs do not perfectly correspond to the average T-score of the population below $-2.5 \mathrm{SD}(-2.74 \mathrm{SD})$ because a population with the average T-score does not have the average fracture risk. Note that the model estimates consequences of vertebral fractures that come to clinical attention whilst the baseline risk of the patient population also is based on the prevalence of morphometric fractures. This method was conservatively used because morphometric vertebral fractures contribute to fracture risk [26] but has unclear consequences for costs and quality of life.

\section{Data}

All data in the model were derived from Swedish sources with the exception of efficacy data and some of the data used to estimate relative risks of fractures and relative risks of mortality from "other fractures". A summary of data inputs and references is shown in Tables 2 and 3.

\section{Costs and discounting}

Fracture and unit costs were in 2008 values whereas the most recent drug costs were used. All costs were collected from a societal perspective and are stated in Euro $(€)$ and translated from Swedish kronor (SEK) when needed with the SEK/€ average exchange rate of 10.59 for the last 12 months (October 2008 to September 2009) [27]. When needed, the costs were inflated using OECD Consumer Price Index statistics. In accordance with Swedish recommendations a yearly discount rate of $3 \%$ was used for both costs and effects [28].

\section{Cost and incidence of fractures}

Costs for vertebral fractures were based on a non representative sample (predominantly those coming to hospital attention $[29,30]$ ) and were therefore adjusted with the hospitalized share of fractures in Sweden to estimate the average cost of a clinical vertebral fracture. To calculate the cost of "other fractures" it was assumed that femoral and pelvic fractures were equivalent to hip fractures; humerus fractures were assumed to be equivalent to vertebral fractures; and fractures to the rib, clavicle, scapula, and sternum were assumed to be equivalent to wrist fractures. The costs were then age-weighted to represent the age distribution of these fractures [31]. Fracture incidences were based on a population-based study from southern Sweden [31,32]. Costs for the second and following years after hip fracture were based on the probability of a first admission to a nursing home 1 year after a hip fracture. Patients residing in a nursing home were assumed to remain there for the rest of their lives [33]. Wrist, vertebral, and other fractures were assumed not to be associated with any costs beyond the first year. 


\section{Cost of intervention}

The monitoring of orally administered osteoporosis therapies was assumed to comprise a yearly visit to a physician visit and a bone mineral density measurement every second year $[9,33]$. Since denosumab is administered by subcutaneous injection 6-monthly, the cost for two nurse visits yearly was added. Intervention and monitoring costs were continued for as long as the patient took treatment.

\section{Cost in added life years}

The difference between consumption and production [34], commonly referred to as cost in added life years (CIALY), was included, as recommended by academic researchers [35] and in Swedish guideline development [28]. Given that a population's production is lower than its consumption above the age of 65 years, the inclusion of this cost will generate a nonmedical cost of increased longevity in the elderly. Cost-effectiveness without inclusion of cost in added years of life was also examined.

\section{Quality of life}

Fracture-related quality of life (QoL) loss was primarily based on a Swedish study that collected QoL at different times during 18 months after hip, vertebral, and wrist fractures, and calculated as a multiple of age-specific QoL score for the general Swedish population $[29,30]$. Normal population QoL tariffs [36] and fracture-related utility multipliers were both based on EQ-5D. All EQ-5D estimates were linked to health state utilities using the algorithm suggested by Dolan [37].

\section{Mortality}

Age-specific mortality rates for the general population in Sweden were based on the year 2008 [38]. The mortality in patients with hip fractures was estimated from 36,551 Swedish women with an s72 (ICD-10) main diagnosis between 1997 and 2001 [39]. Mortality during the first year after hip fracture was, due to the initial steep hazard decline, estimated with a Poisson model and mortality during second and following years was estimated with a parametric Weibull model. Mortality for the second and following years was calculated as an average for years 2-5. Standardized mortality ratios (SMRs; Table 2) were calculated by dividing the estimated mortalities by the Swedish age-matched female normal population mortality for 2000 [38].

Even when the mortality is adjusted for BMD and co-morbid conditions, patients with osteoporotic vertebral fractures have been shown to have a significantly higher mortality compared to osteoporotic patients without fracture [40, 41]. Age-differentiated mortality after clinical vertebral fractures was derived from Johnell et al. [42]. The Poisson model that was used (personal communication Olof Johnell 2006-04-20) is shown below.

$$
y_{t}=e^{-4.815-0.631+\text { age } \times 0.04548-\text { years from fracture } \times 0.176}
$$


SMRs were created in the same way as for hip fractures, but with the general population mortality for 1994 [38]. Mortality in the first year after "other fractures" [43] was combined with the Swedish distribution of "other fractures" [31]. The age variation in fracture distribution was small and a SMR of 1.22 was estimated for all age groups. Wrist fracture was assumed to not be associated with increased mortality. Persons with osteoporosis have a higher degree of frailty compared to the general population, and excess mortality after an osteoporotic fracture is not entirely attributed to the fracture event [44-46]. Thus, in agreement with previous health economic studies [8-10], it was assumed that $30 \%$ of the excess mortality after hip, vertebral, and other fractures was associated with the event. The duration of increased mortality was assumed to be 8 years, which was the duration of follow-up in the two studies by Kanis et al. [44, 46], but was varied in sensitivity analysis.

\section{Results}

Base case

Table 4 shows the cost-effectiveness estimates for denosumab compared with "no treatment", generic alendronate, risedronate, and strontium ranelate for the base-case scenario. The cost-effectiveness ratio is determined by the differences in costs and outcome (QALY) for the alternatives compared. Denosumab was the most costly treatment alternative, but also had the best effectiveness resulting in larger morbidity cost savings and higher number of QALYs gained. The low cost-effectiveness ratio of denosumab compared with risedronate or strontium ranelate is a result of a rather small difference in price compared to the difference in effectiveness. The higher cost-effectiveness ratio compared to generic alendronate is mainly explained by a large difference in price, which is only partly offset by improved effectiveness. The cost-effectiveness ratio in the comparison of denosumab with "no treatment" is directly estimated from the clinical trials. Further, "no treatment" is the relevant comparator for patients that do not adhere to available low cost treatments. Cost-effectiveness of denosumab improved when CIALY was excluded from the analysis because avoided fractures then included survival benefits in the QALYs gained, but no consumption costs due to increased longevity.

The estimated differences in treatment cost (Table 4) between denosumab and the active comparators were larger than the differences in drug price (Table 3) because of the additional nurse visits associated with denosumab and because patients remained longer on treatment. The same pattern was seen for health outcomes and avoided morbidity costs because more fractures were avoided, compared with the oral treatments, than would be inferred from the efficacy data alone (Table 1).

Because generic alendronate is both lower priced and more efficacious it was estimated to be cost saving when compared with risedronate and strontium ranelate. Furthermore, risedronate was cost saving compared with strontium ranelate, if those were to be the only two treatment options. 


\section{Persistence}

The improved persistence that was assumed for denosumab compared with other agents had a markedly different impact on incremental cost-effectiveness depending on the comparator (Fig. 2). The comparison with the low-priced generic alendronate showed a marked effect with reduction in discontinuation rates. If patients on denosumab were equally persistent as patients on alendronate $(\mathrm{RR}=1.0)$, the incremental cost-effectiveness ratio (ICER) was close to $€ 60,000$ per QALY gained, but fell to below $€ 50,000$ if the risk of discontinuation was reduced by only $10 \%$. The impact was considerably smaller when denosumab was compared with a more similarly priced treatment, such as risedronate. The reason is that poor persistence with risedronate saves more treatment costs, and improved persistence with denosumab had thus a smaller relative impact. In the comparison with strontium ranelate, which has nearly the same price as denosumab, but has a smaller risk reduction, the costeffectiveness ratio worsened when fewer patients discontinued Dmab treatment. This is because the relative cost increase from improved persistence with denosumab is larger than the relative QALY increase. And since the cost/QALY is a ratio of two differences $\left(\mathrm{Cost}_{\mathrm{B}}\right.$ $\operatorname{Cost}_{\mathrm{A}} / \mathrm{QALY}_{\mathrm{B}}-\mathrm{QALY}_{\mathrm{A}}$ ) the ratio increased in the comparison with strontium ranelate. In general, when the discontinuation rate for denosumab was decreased, all comparisons moved towards the cost per QALY for denosumab compared with no treatment.

When denosumab users were assumed to have the same persistence as alendronate users, it was estimated that denosumab would avoid 1.7 hip fractures and 13.6 clinical vertebral fractures per 1,000 patients followed for 10 years compared with alendronate. In the corresponding base-case scenario where denosumab users were $46 \%$ (RR 0.54 ) less likely to discontinue treatment, 14.2 hip fractures and 35.7 clinical vertebral fractures were avoided (Fig. 3).

\section{Fracture risk}

The incremental cost-effectiveness of denosumab was explored in relation to fracture risk as defined by T-score and prevalence of vertebral morphometric fracture (Fig. 4). Data are shown for populations at a specific T-score, rather than at or below, as given for the base case. All comparisons showed, as expected, that cost-effectiveness improved with decreasing T-score, i.e., an increasing baseline risk. For patients with prior fracture, the cost per QALY was lower, and denosumab was cost saving compared with no treatment in patients with a prior fracture and a $\mathrm{T}$-score of about $-3.7 \mathrm{SD}$ or lower.

\section{Age at starting treatment}

In addition to decreasing T-score and prior vertebral fracture, the age of the treated population was an important determinant of fracture risk (Fig. 5). Cost-effectiveness of denosumab compared with no treatment or other comparators improved with increasing age.

\section{Other sensitivity analyses}

A range of sensitivity analyses around the base-case scenario is shown in Table 5. Results comparing denosumab with generic alendronate were more sensitive to changing assumptions than other comparisons due to the lower price of generic alendronate and the smaller QALY gains compared with denosumab. Changing the assumptions about the 
superior persistence for denosumab, for example applying the persistence improvement found in the DAPS study for only the first 12 months, the ICER for denosumab vs. generic alendronate worsened markedly whilst the impact was less for other comparators. The ICER for denosumab vs. generic alendronate and denosumab vs. risedronate improved somewhat when gastrointestinal adverse events were included. Assumptions about offset time after treatment was stopped had a significant impact on the ICER because it provided some "free" effect for no cost but did not change the relationship between alternative treatments. But assuming a treatment-differentiated offset, where denosumab treatment had a maximum offset of 2 years (and 5 years for the comparators), resulted in ICERs of approximately $€ 20,000, € 41,000, € 20,000$, and $€ 11,000$ compared with no treatment, generic alendronate, risedronate, and strontium, respectively. Extending the duration of treatment had little net effect on incremental cost-effectiveness. Cost-effectiveness of denosumab improved slightly when less mortality was attributed to fractures or when mortality was applied for a shorter time after fractures. This unintuitive effect was caused by that the reduced "cost in added life years" had a larger relative impact than the corresponding reduction in gained QALYs.

\section{Discussion}

This study estimated the cost-effectiveness of denosumab compared with "no treatment", generic alendronate, risedronate, and strontium ranelate. The base-case population was chosen to represent the average patient treated for postmenopausal osteoporosis in Sweden. The basic model structure is well validated and similar to previously published models [810]. The main difference was the incorporation of adherence, which is seldom explicitly included in cost-effectiveness models. The principal findings of the present study is that treatment with denosumab added to the expected costs of treatment compared to all four alternatives, but the incremental cost-effectiveness ratio in all cases was below commonly used threshold values of €50-60,000 per QALY gained.

\section{Denosumab compared with other treatments}

In the present study, treatment with denosumab resulted in generally higher expected treatment costs compared with other treatments. This was particularly marked in the comparison of denosumab with generic alendronate. The higher ICER when denosumab was compared to alendronate than when compared to other treatments, is a result of the significant reduction in price of alendronate after its patent expiration. This price reduction markedly improved the cost-effectiveness of a drug that, based on clinical trial data, had been already shown to be cost-effective in relevant patient populations [8]. The ICER for denosumab vs generic alendronate noted in the present study ( $€ 27,000)$ is of a magnitude that could justify the choice of denosumab for the typical patient on the grounds of costeffectiveness. Moreover, the majority of patients will discontinue treatment with alendronate and, as discussed below, the higher the risk of non-adherence, the better the costeffectiveness for denosumab.

When including cost in added life years in the base-case denosumab was penalized because avoided fracture-related deaths were associated with increased consumption costs in the elderly. CIALY was also the reason why decreasing the fraction of attributable post-fracture 
mortality in sensitivity analysis was associated with improved cost-effectiveness of denosumab. CIALY is rarely included in cost-effectiveness analyses, and this is likely due to limited demand from regulators and payers.

The comparison between treatments is fraught with difficulties. A major problem is that there are no comparator studies that evaluate fractures as the primary outcome. Hence the efficacy of each agent is taken from meta-analyses of RCTs versus placebo. The baseline characteristics, including fracture risk vary widely between studies and there is reason to suppose that responsiveness to an intervention differs according to the type of patient enrolled. Examples are provided in the Fracture Intervention Trials (FIT) with alendronate $[47,48]$ and the hip fracture studies with risedronate [49] where the relative risk reductions in active treatment arms varied between studies of the same agent. More recently, greater efficacy of clodronate and bazedoxifene has been observed in patients with higher pretreatment fracture probabilities as assessed by FRAX [50,51]. These considerations suggest that in the context of cost-effectiveness, there is much greater uncertainty over incremental efficacy than incremental costs or even comparative persistence. With these limitations, it is reasonable that alendronate can be considered as a first line treatment, but that denosumab may be a cost-effective alternative in patients that are at higher risk of fracture or likely to discontinue treatment.

\section{Denosumab compared with no treatment}

An important finding of the present study is that denosumab compared with no treatment has a cost-effectiveness ratio that is less than half of that which is generally accepted as "costeffective" $[8,52]$.

Denosumab compared with no treatment is the relevant comparison for patients that will not adhere to oral therapy or may be expected to stop treatment after a rather short time. As noted above, the majority of women given bisphosphonates stop treatment within 1 or 2 years. An optimal management approach from a cost-effectiveness perspective would thus be to prescribe generic alendronate for those patients with a high likelihood of good adherence, and denosumab for patients likely to have a low adherence or to prescribe generic alendronate first, and switch if patients do not adhere.

The present study also showed that cost-effectiveness of denosumab improved markedly with advancing age and worsening T-score. This is to be expected since both contribute to fracture risk and the benefits of intervention are correspondingly increased. Treatment with denosumab became cost saving compared with no treatment in patients aged 71 years with a T-score for BMD of $-3.7 \mathrm{SD}$ in women with a prior fracture. In the case of increasing age, denosumab became cost saving compared with no treatment in women from the age of 80 years with or without a prior vertebral fracture. Thus, denosumab may be considered as a first line treatment for patients at high risk where the risk of non-adherence is high.

\section{Persistence}

Lack of adherence to therapy is a major problem in the management of osteoporosis. Costeffectiveness studies based on clinical trial information have shown that treatment of osteoporosis is a cost-effective intervention for the patients with a risk of fracture defined in 
clinical trials and guidelines for intervention $[8,53]$. However, the adherence to therapy in clinical practice, both patient-reported and register-based, is much lower than in clinical trials [20,54]. This does not invariably change the cost-effectiveness of the intervention when compared with no treatment, since patients who drop out of treatment lose both costs and effects. However this outcome leaves large groups of patients untreated, such that the public health objectives of fracture reduction are not met. Improving persistence had a considerable impact on the number of avoided fractures. The reduced dropout rate used in the base case $(R R=0.54)$ resulted in 28 and 54 avoided hip and vertebral fractures per 1,000 treated patients (compared with no treatment). Fifteen hip fractures and 32 vertebral fractures were avoided in the corresponding scenario where denosumab users would not be more persistent than has been estimated for oral therapies.

In previous economic studies accounting for persistence [55, 56], including one commissioned by the UK National Institute for Health and Clinical Excellence [56], it was assumed that $20-80 \%$ of patients completed the full 5-year course, with the remaining patients receiving 3 months of drug costs but no health gain. A problem with such an approach is that those who discontinue treatment are likely to do so at time points throughout the 5-year period and should thus receive some health benefit, as well as additional drug costs. A novel feature of the present study is that it incorporated adherence in a more realistic manner than hitherto and gave patients a longer offset time if they remained on treatment longer. This will naturally benefit treatments with a favorable persistence profile.

In the base-case comparing denosumab with "no treatment", the ICER was approximately $€ 14,500$ and sensitivity analysis showed that this result was modestly affected by persistence. The ICER fell to $€ 11,900$ with perfect persistence for denosumab (i.e. 5 years) and rose to $€ 15,900$ when a persistence advantage was limited to 1 year. The relatively small impact on cost-effectiveness arises because the extra QALYs from longer treatment were largely offset by higher treatment costs.

The comparisons with the other marketed treatments were more complex and some results were very sensitive to improved persistence. The effect was most marked in the comparison of denosumab with generic alendronate. As persistence of denosumab increased (keeping the persistence of alendronate constant), the ICER decreased progressively (see Fig. 2). For example, where persistence of denosumab was modeled at the same persistence as that estimated for alendronate from prescription data, the ICER was $€ 57,000$. At the base case, the ICER was $€ 27,000$ and fell still further with further improvement in the persistence of denosumab compared to that of alendronate. The impact of persistence was considerably smaller, or even negative, when denosumab was compared with the more expensively priced treatments. The reason is that poor persistence saved more treatment costs, and improved persistence with denosumab had, therefore, a smaller relative impact.

Thus differences in drug price had a major impact on ICER, though differences in efficacy and offset time will also govern the impact of improved persistence [7]. It is of interest that treatment with denosumab increased the total cost when compared to other treatments. However, in the base case, the incremental cost-effectiveness ratio in all cases was below 
commonly used thresholds of $€ 50-60,000$ per QALY gained. The robustness of this observation depends on the assumption that 6-monthly treatment with denosumab reduced discontinuation rates by $46 \%$, as observed in the DAPS study. It is notable that the absolute discontinuation rate observed for alendronate in the DAPS study (20.2\% after 12 months) was lower than estimates from prescription and claims data (53\% after 12 months) [11] which may reflect the impact of the trial setting. It is also not known if the reduced discontinuation rates observed during the first 12 months of treatment can be maintained for longer periods. It is not yet possible to derive persistence patterns with denosumab in clinical practice thus the results from the DAPS study represent the best available information to date.

Prescription refill gaps were not included in this study because such gaps were uncommon in the Swedish prescription data underlying this analysis and because no clear association between MPR and fracture risk was established [57]. This may be due to cultural differences and logistic factors in the Swedish pharmacy system and that MPR in the Swedish study [11] was estimated only in persistent patients. It is also difficult to establish whether the association between MPR and fracture risk [5] is causal since non-compliant patients have higher co-morbidity rates, are more frail, and have higher health-care expenditures than compliant patients $[58,59]$ and rates are rarely adjusted for confounders. Moreover, fracture rates are higher in non-compliant patients taking placebo [59]. A further limitation with MPR is that it only covers treatment gaps and compliance should ideally also include other aspects that impact outcomes, such as how and when doses are taken.

The persistence data used in this analysis (with the exception of denosumab) were taken from the Swedish prescription register. It is likely that drug persistence is dependent on a number of factors, such as drug costs, insurance status, and cultural setting, and may thus vary between countries. If persistence rates vary between settings, so will the costeffectiveness of improving it. Thus, when evaluating the cost-effectiveness of drugs that improve persistence and/or compliance, country-specific data should be used where possible, not only for fracture risks and costs, but also for adherence.

\section{Offset time}

A "reference standard" in osteoporosis modeling in the bisphosphonate era has been that the offset time is assumed to be equal to the period of treatment. Since 5-year treatments are common a 5-year treatment offset is usually modeled $[60,61]$. The rationale for this arises from the notion that the effects of a short-term treatment on fracture risk are unlikely to persist indefinitely and equally unlikely to disappear as soon as treatment is stopped. As noted in this study and by others $[8,62]$, relatively small variations in offset time can have a marked effect on cost-effectiveness. A reduction in offset time from the base case to a maximum of 2 years decreased the cost-effectiveness of denosumab, with an increase in the ICER from $€ 14,500$ to $€ 19,900$. Empirical data are scanty and indeed the study of offset has been identified as an important component of drug development [63], though not a requirement for registration of new agents.

A variety of studies has attempted to address offset time from randomized controlled studies or observational studies. The most complete study available is for teriparatide where 
sustained effects on fracture outcomes were observed for up to 30 months after discontinuing treatment with follow-up of the placebo and treatment arms of the study [64]. A sustained effect of hormone replacement treatment for up to 15 years has been reported from a follow-up of three RCTs [65-67]. It is notable however, that shorter offset times are inconsistently reported in some observational studies with hormone replacement therapy (HRT) $[68,69]$. In the case of the bisphosphonates, the FLEX study [70] compared alendronate to placebo for 5 years following a 5-year treatment with alendronate in the FIT trial. A prolonged offset time for non-vertebral fracture risk was reported, but the certainty of the conclusion is questionable. As is the case of HRT, observational studies have reported more rapid reversal of effect on stopping treatment $[71,72]$ No direct information is available for strontium ranelate or denosumab.

In the absence of information on fracture outcomes, inferences have been made from surrogates such as post-treatment changes in the biochemical markers of bone turnover or BMD [69, 72-75]. At present, there is no robust evidence to define an offset time with greater accuracy than the "reference" assumption and no direct evidence to support differential offsets between treatments and we therefore assumed 5 years of maximum offset for all treatments in the base case.

\section{Limitations}

In addition to data gaps that need to be filled to more accurately estimate cost-effectiveness of therapies with different persistence profiles, information is also lacking on the relation between treatment duration and offset time. Other aspects of adherence such as switching, primary non-adherence, and onset time have been shown to be of lesser importance due to cost offsets and scenarios where patients with both poor and satisfactory treatment adherence are affected similarly [7]. For this reason, these uncertainties were not addressed in the present analysis.

This model construct has some limitations. The cohort methodology utilizes a hierarchical structure that gives rise to a small underestimate of the number of less-severe fractures in the cohort. Cohort models also lack the possibility to track multiple fractures in individual patients and instead distribute them as an average number of fractures over the cohort. Most microsimulation models (i.e. with memory of disease history) can accommodate these multiple fractures but, due to the paucity of data, only consider the worst consequences at any given time [73-75]. Thus, the consequences of the "missed" fractures or multiple fractures in one individual would anyway have been largely disregarded in a microsimulation framework. Further, cohort models have the advantage of simulation speed and are not burdened with 1st order uncertainty (random noise that depends on the number of simulations) that can distort result interpretation in scenarios where small QALY gains and cost differences are estimated.

\section{Conclusion}

Incomplete adherence to therapy is a major problem in the treatment of osteoporosis and means that patients at high risk of fracture indicated for therapy are not treated. Improving persistence with osteoporosis treatment would lend significant contribution to a further 
reduction of osteoporosis-related fractures. Denosumab offers a cost-effective alternative and complement to existing oral osteoporosis treatments, and may be considered a first line option in Swedish patients at high risk of fracture and non-adherence.

\section{Acknowledgments}

The authors would like to acknowledge Amgen Inc. Thousand Oaks, CA, USA for funding model development and Steering Committee meetings. The authors are also grateful to Enkhe Badamgarav and David Macarios of Amgen Inc. and Deborah Marshall of the University of Calgary for their assistance in framing the research questions, aid in model development, and participation in the Steering Committee. The authors also sincerely appreciate the tremendous logistical and planning support provided by Dominika Dabrowski of i3 Innovus.

\section{References}

1. Kanis JA, Johnell O. Requirements for DXA for the management of osteoporosis in Europe. Osteoporos Int. 2005; 16:229-238. [PubMed: 15618996]

2. Delmas PD. Treatment of postmenopausal osteoporosis. Lancet. 2002; 359:2018-2026. [PubMed: 12076571]

3. Murthy RK, Morrow PK, Theriault RL. Bone biology and the role of the RANK ligand pathway. Oncology (Williston Park). 2009; 23:9-15. [PubMed: 20128323]

4. Cummings SR, San Martin J, McClung MR, Siris ES, Eastell R, Reid IR, Delmas P, Zoog HB, Austin M, Wang A, Kutilek S, Adami S, Zanchetta J, Libanati C, Siddhanti S, Christiansen C. Denosumab for prevention of fractures in postmenopausal women with osteoporosis. N Engl J Med. 2009; 361:756-765. [PubMed: 19671655]

5. Siris ES, Harris ST, Rosen CJ, Barr CE, Arvesen JN, Abbott TA, Silverman S. Adherence to bisphosphonate therapy and fracture rates in osteoporotic women: relationship to vertebral and nonvertebral fractures from 2 US claims databases. Mayo Clin Proc. 2006; 81:1013-1022. [PubMed: 16901023]

6. Papaioannou A, Ioannidis G, Adachi JD, Sebaldt RJ, Ferko N, Puglia M, Brown J, Tenenhouse A, Olszynski WP, Boulos P, Hanley DA, Josse R, Murray TM, Petrie A, Goldsmith CH. Adherence to bisphosphonates and hormone replacement therapy in a tertiary care setting of patients in the CANDOO database. Osteoporos Int. 2003; 14:808-813. [PubMed: 14523610]

7. Strom O, Borgstrom F, Kanis JA, Jonsson B. Incorporating adherence into health economic modelling of osteoporosis. Osteoporos Int. 2009; 20:23-34. [PubMed: 18521650]

8. Strom O, Borgstrom F, Sen SS, Boonen S, Haentjens P, Johnell O, Kanis JA. Cost-effectiveness of alendronate in the treatment of postmenopausal women in 9 European countries-an economic evaluation based on the fracture intervention trial. Osteoporos Int. 2007; 18:1047-1061. [PubMed: 17333449]

9. Borgstrom F, Jonsson B, Strom O, Kanis JA. An economic evaluation of strontium ranelate in the treatment of osteoporosis in a Swedish setting: based on the results of the SOTI and TROPOS trials. Osteoporos Int. 2006; 17:1781-1793. [PubMed: 17009083]

10. Kanis JA, Adams J, Borgstrom F, Cooper C, Jonsson B, Preedy D, Selby P, Compston J. The costeffectiveness of alendronate in the management of osteoporosis. Bone. 2008; 42:4-15. [PubMed: 18156107]

11. Landfeldt, E., Borgström, F., Robbins, S., Ström, O. A retrospective cohort study of medication adherence to treatment of osteoporosis in a Swedish population. Oral presentation, ISPOR; Paris. 2009.

12. Kanis, J. Technical Report. WHO Collaborating Centre for Metabolic Bone Diseases, University of Sheffield; UK: 2008. Assessment of osteoporosis at the primary health-care level; p. 61

13. Medical products agency. Behandling av osteoporos. 2007. www.mpa.se

14. Felsenberg D, Silman A, Lunt M, Ambrecht G, Ismail A. Incidence of vertebral fracture in Europe: results from the European prospective osteoporosis study (EPOS). J Bone Miner Res. 2002; 17:716-724. [PubMed: 11918229] 
15. Hasserius R, Karlsson MK, Nilsson BE, Redlund-Johnell I, Johnell O. Prevalent vertebral deformities predict increased mortality and increased fracture rate in both men and women: a 10year population-based study of 598 individuals from the Swedish cohort in the European Vertebral Osteoporosis Study. Osteoporos Int. 2003; 14:61-68. [PubMed: 12577186]

16. NICE. Systematic reviews of clinical effectiveness prepared for the guideline Osteoporosis: "Assessment of fracture risk and the prevention of osteoporotic fractures in individuals at high risk". 2008. (http://wwwniceorguk/guidance/indexjsp?action=byID\&o=11621)

17. Jones, ML., Wilkinson, A. Adverse effects and persistence with therapy in patients taking oral alendronate, etidronate or residronate: systematic reviews (NICE). The University of Sheffield, School of Health and Related Research; 2006. (http://www.nice.org.uk/guidance/index.jsp? action=download\&o=36718)

18. Stevenson, M., Davis, S. DSU economic evaluation of pooled alendronate and risedronate compared with strontium ranelate, raloxifene, etidronate and teriparatide. National Institute of Clinical Exelence (NICE); 2006. http://www.nice.org.uk/page.aspx?o=370643 [Accessed 13 May 2009]

19. Reginster JY, Bruyere O, Sawicki A, Roces-Varela A, Fardellone P, Roberts A, Devogelaer JP. Long-term treatment of postmenopausal osteoporosis with strontium ranelate: results at 8 years. Bone. 2009; 45:1059-1064. [PubMed: 19679207]

20. Kothawala P, Badamgarav E, Ryu S, Miller RM, Halbert RJ. Systematic review and meta-analysis of real-world adherence to drug therapy for osteoporosis. Mayo Clin Proc. 2007; 82:1493-1501. [PubMed: 18053457]

21. McClung M, Freemantle N, Kendler D, Lillestol M, Moffett A, Satram-Hoang S, Yang Y, Kaur P, Macarios D, Siddhanti S. Open-label study to evaluate the adherence, preference, and satisfaction of denosumab and alendronate in postmenopausal women. S 386 Osteoporos Int. 2010; 21(Suppl 1) S25-S388 1 C P899.

22. Kanis JA, Borgstrom F, Johnell O, Oden A, Sykes D, Jonsson B. Cost-effectiveness of raloxifene in the UK: an economic evaluation based on the MORE study. Osteoporos Int. 2005; 16:15-25. [PubMed: 15672210]

23. Kanis JA, Johnell O, Oden A, Jonsson B, Dawson A, Dere W. Risk of hip fracture derived from relative risks: an analysis applied to the population of Sweden. Osteoporos Int. 2000; 11:120-127. [PubMed: 10793869]

24. De Laet CE, van Hout BA, Burger H, Hofman A, Pols HA. Bone density and risk of hip fracture in men and women: cross sectional analysis. Br Med J. 1997; 315:221-225. [PubMed: 9253270]

25. Johnell O, Kanis JA, Oden A, Johansson H, De Laet C, Delmas P, Eisman JA, Fujiwara S, Kroger H, Mellstrom D, Meunier PJ, Melton LJ 3rd, O'Neill T, Pols H, Reeve J, Silman A, Tenenhouse A. Predictive value of BMD for hip and other fractures. J Bone Miner Res. 2005; 20:1185-1194. [PubMed: 15940371]

26. Klotzbuecher CM, Ross PD, Landsman PB, Abbott TA 3rd, Berger M. Patients with prior fractures have an increased risk of future fractures: a summary of the literature and statistical synthesis. J Bone Miner Res. 2000; 15:721-739. [PubMed: 10780864]

27. [Accessed 18 October 2009] Average Exchange Rates. http://www.riksbank.com

28. Dental and Pharmaceutical Benefits Agency. General guidelines for economic evaluations from the Pharmaceutical Benefits Board. 2003. www.tlv.se

29. Borgstrom F, Zethraeus N, Johnell O, Lidgren L, Ponzer S, Svensson O, Abdon P, Ornstein E, Lunsjo K, Thorngren KG, Sernbo I, Rehnberg C, Jonsson B. Costs and quality of life associated with osteoporosis-related fractures in Sweden. Osteoporos Int. 2006; 17:637-650. [PubMed: 16283064]

30. Ström O, Borgstrom F, Zethraeus N, Johnell O, Lidgren L, Ponzer S, Svensson O, Abdon P, Ornstein E, Ceder L, Thorngren KG, Sernbo I, Jonsson B. Long-term cost and effect on quality of life of osteoporosis-related fractures in Sweden. Acta Orthop. 2008; 79:269-280. [PubMed: 18484255]

31. Kanis JA, Oden A, Johnell O, Jonsson B, de Laet C, Dawson A. The burden of osteoporotic fractures: a method for setting intervention thresholds. Osteoporos Int. 2001; 12:417-427. [PubMed: 11444092] 
32. Kanis JA, Johnell O, Oden A, Sembo I, Redlund-Johnell I, Dawson A, De Laet C, Jonsson B. Long-term risk of osteoporotic fracture in Malmo. Osteoporos Int. 2000; 11:669-674. [PubMed: 11095169]

33. Jonsson B, Christiansen C, Johnell O, Hedbrandt J. Cost-effectiveness of fracture prevention in established osteoporosis. Osteoporos Int. 1995; 5:136-142. [PubMed: 7599450]

34. Ekman, M. [Accessed 2009-12-11] Consumption and production by age in Sweden: Basic facts and health economic implications. 2002. http://www.tlv.se/Upload/Foretag/FOR-040506-tabelllakemedel.pdf

35. Johanesson, M., Jonsson, B., Jonsson, L., Kobelt, G., Zethraeus, N. Office of healt economics (OHE). 2009 Oct. Why should economic evaluations of medical innovations have a societal perspective?.

36. Burstrom K, Johannesson M, Diderichsen F. Swedish population health-related quality of life results using the EQ-5D. Qual Life Res. 2001; 10:621-635. [PubMed: 11822795]

37. Dolan P. Modeling valuations for EuroQol health states. Med Care. 1997; 35:1095-1108. [PubMed: 9366889]

38. [Accessed 2010-03-16] Statistics Sweden. http://www.ssd.scb.se/databaser/makro/Produkt.asp? produktid=BE0101

39. The National Board of Health and Welfare. National Patient Register (NPC) and Cause of Death Register (CDR). http://www.sos.se/epc/epceng.htm

40. Ioannidis G, Papaioannou A, Hopman WM, Akhtar-Danesh N, Anastassiades T, Pickard L, Kennedy CC, Prior JC, Olszynski WP, Davison KS, Goltzman D, Thabane L, Gafni A, Papadimitropoulos EA, Brown JP, Josse RG, Hanley DA, Adachi JD. Relation between fractures and mortality: results from the Canadian Multi-centre Osteoporosis Study. Cmaj. 2009; 181:265271. [PubMed: 19654194]

41. Center JR, Nguyen TV, Schneider D, Sambrook PN, Eisman JA. Mortality after all major types of osteoporotic fracture in men and women: an observational study. Lancet. 1999; 353:878-882. [PubMed: 10093980]

42. Johnell O, Kanis JA, Oden A, Sernbo I, Redlund-Johnell I, Petterson C, De Laet C, Jonsson B. Mortality after osteoporotic fractures. Osteoporos Int. 2004; 15:38-42. [PubMed: 14593451]

43. Barrett JA, Baron JA, Beach ML. Mortality and pulmonary embolism after fracture in the elderly. Osteoporos Int. 2003; 14:889-894. [PubMed: 12942231]

44. Kanis JA, Oden A, Johnell O, De Laet C, Jonsson B. Excess mortality after hospitalisation for vertebral fracture. Osteoporos Int. 2004; 15:108-112. [PubMed: 14598026]

45. Bliuc D, Nguyen ND, Milch VE, Nguyen TV, Eisman JA, Center JR. Mortality risk associated with low-trauma osteoporotic fracture and subsequent fracture in men and women. Jama. 2009; 301:513-521. [PubMed: 19190316]

46. Kanis JA, Oden A, Johnell O, De Laet C, Jonsson B, Oglesby AK. The components of excess mortality after hip fracture. Bone. 2003; 32:468-473. [PubMed: 12753862]

47. Cummings SR, Black DM, Thompson DE, Applegate WB, Barrett-Connor E, Musliner TA, Palermo L, Prineas R, Rubin SM, Scott JC, Vogt T, Wallace R, Yates AJ, LaCroix AZ. Effect of alendronate on risk of fracture in women with low bone density but without vertebral fractures: results from the Fracture Intervention Trial. Jama. 1998; 280:2077-2082. [PubMed: 9875874]

48. Black DM, Cummings SR, Karpf DB, Cauley JA, Thompson DE, Nevitt MC, Bauer DC, Genant HK, Haskell WL, Marcus R, Ott SM, Torner JC, Quandt SA, Reiss TF, Ensrud KE. Randomised trial of effect of alendronate on risk of fracture in women with existing vertebral fractures. Fracture Intervention Trial Research Group. Lancet. 1996; 348:1535-1541. [PubMed: 8950879]

49. McClung MR, Geusens P, Miller PD, Zippel H, Bensen WG, Roux C, Adami S, Fogelman I, Diamond T, Eastell R, Meunier PJ, Reginster JY. Effect of risedronate on the risk of hip fracture in elderly women. Hip Intervention Program Study Group. N Engl J Med. 2001; 344:333-340. [PubMed: 11172164]

50. McCloskey EV, Johansson H, Oden A, Vasireddy S, Kayan K, Pande K, Jalava T, Kanis JA. Tenyear fracture probability identifies women who will benefit from clodronate therapy-additional results from a double-blind, placebo-controlled randomised study. Osteoporos Int. 2009; 20:811817. [PubMed: 19002369] 
51. Kanis JA, Johansson H, Oden A, McCloskey EV. Bazedoxifene reduces vertebral and clinical fractures in postmenopausal women at high risk assessed with FRAX. Bone. 2009; 44:1049-1054. [PubMed: 19254788]

52. Vägverket. Vägverkets samhällsekonomiska kalkymodell. In: Authority, VSR., editor. Ekonomisk teori och värderingar. Stockholm: 1997.

53. Tosteson AN, Burge RT, Marshall DA, Lindsay R. Therapies for treatment of osteoporosis in US women: cost-effectiveness and budget impact considerations. Am J Manag Care. 2008; 14:605615. [PubMed: 18778176]

54. Tosteson AN, Do TP, Wade SW, Anthony MS, Downs RW. Persistence and switching patterns among women with varied osteoporosis medication histories: 12-month results from POSSIBLE US. Osteoporos Int. 2010 (E-pub ahead of print).

55. Kanis JA, Stevenson M, McCloskey EV, Davis S, Lloyd-Jones M. Glucocorticoid-induced osteoporosis: a systematic review and cost-utility analysis. Health Technol Assess. 2007; 11:1256.

56. Stevenson, M., Davies, S. DSU economic evaluation of pooled alendronate and risedronate compared with strontium ranelate, raloxifene, etidronate and teriparatide. 2006. (http:// guidance.nice.org.uk/page.aspx?o=370643)

57. Ström, O., Landfeldt, E., Robbins, S., Borgström, F. Adherence to treatment of osteoporosis and fracture risk: The Swedish Adherence Register Analysis (SARA). Oral presentation/poster ECCEO/IOF; Florence. 2010.

58. Huybrechts KF, Ishak KJ, Caro JJ. Assessment of compliance with osteoporosis treatment and its consequences in a managed care population. Bone. 2006; 38:922-928. [PubMed: 16330270]

59. McCloskey E, De Takats D, Orgee J, Aropinn S, Jalava T, Cliffe J, Reaney L, McGurk C, Charlesworth DJAK. Characteristics associated with non-persistence during daily therapy. Experience from the placebo wing of a community based clinical trial. J Bone Miner Res. 2005; 20(suppl 1):S282.

60. Jonsson B, Kanis J, Dawson A, Oden A, Johnell O. Effect and offset of effect of treatments for hip fracture on health outcomes. Osteoporos Int. 1999; 10:193-199. [PubMed: 10525710]

61. Kanis JA, Jonsson B. Economic evaluation of interventions for osteoporosis. Osteoporos Int. 2002; 13:765-767. [PubMed: 12378364]

62. Kanis JA, Borgstrom F, Johnell O, Jonsson B. Cost-effectiveness of risedronate for the treatment of osteoporosis and prevention of fractures in postmenopausal women. Osteoporos Int. 2004; 15:862871. [PubMed: 15175846]

63. WHO. Guidelines for preclinical evaluation and clinical trials in osteoporosis. Geneve: 1998. http:// whqlibdoc.who.int/publications/1998/9241545224_eng.pdf, Accessed

64. Prince R, Sipos A, Hossain A, Syversen U, Ish-Shalom S, Marcinowska E, Halse J, Lindsay R, Dalsky GP, Mitlak BH. Sustained nonvertebral fragility fracture risk reduction after discontinuation of teriparatide treatment. J Bone Miner Res. 2005; 20:1507-1513. [PubMed: 16059622]

65. Greendale GA, Espeland M, Slone S, Marcus R, Barrett-Connor E. Bone mass response to discontinuation of long-term hormone replacement therapy: results from the Postmenopausal Estrogen/Progestin Interventions (PEPI) Safety Follow-up Study. Arch Intern Med. 2002; 162:665-672. [PubMed: 11911720]

66. Bagger YZ, Tanko LB, Alexandersen P, Hansen HB, Mollgaard A, Ravn P, Qvist P, Kanis JA, Christiansen $\mathrm{C}$. Two to three years of hormone replacement treatment in healthy women have long-term preventive effects on bone mass and osteoporotic fractures: the PERF study. Bone. 2004; 34:728-735. [PubMed: 15050905]

67. Christiansen C, Christensen MS, Transbol I. Bone mass in postmenopausal women after withdrawal of oestrogen/gestagen replacement therapy. Lancet. 1981; 1:459-461. [PubMed: 6110089]

68. Cauley JA, Seeley DG, Ensrud K, Ettinger B, Black D, Cummings SR. Estrogen replacement therapy and fractures in older women. Study of Osteoporotic Fractures Research Group. Ann Intern Med. 1995; 122:9-16. [PubMed: 7985914] 
69. Banks E, Beral V, Reeves G, Balkwill A, Barnes I. Fracture incidence in relation to the pattern of use of hormone therapy in postmenopausal women. Jama. 2004; 291:2212-2220. [PubMed: 15138243]

70. Black DM, Schwartz AV, Ensrud KE, Cauley JA, Levis S, Quandt SA, Satterfield S, Wallace RB, Bauer DC, Palermo L, Wehren LE, Lombardi A, Santora AC, Cummings SR. Effects of continuing or stopping alendronate after 5 years of treatment: the Fracture Intervention Trial Long-term Extension (FLEX): a randomized trial. Jama. 2006; 296:2927-2938. [PubMed: 17190893]

71. Gallagher AM, Rietbrock S, Olson M, van Staa TP. Fracture outcomes related to persistence and compliance with oral bisphosphonates. J Bone Miner Res. 2008; 23:1569-1575. [PubMed: 18505366]

72. Curtis JR, Westfall AO, Cheng H, Delzell E, Saag KG. Risk of hip fracture after bisphosphonate discontinuation: implications for a drug holiday. Osteoporos Int. 2008; 19:1613-1620. [PubMed: 18483689]

73. Lekander I, Borgstrom F, Strom O, Zethraeus N, Kanis JA. Cost effectiveness of hormone therapy in women at high risks of fracture in Sweden, the US and the UK-Results based on the Women's Health Initiative randomised controlled trial. Bone. 2008; 42:294-306. [PubMed: 18053789]

74. Zethraeus N, Borgstrom F, Jonsson B, Kanis J. Reassessment of the cost-effectiveness of hormone replacement therapy in Sweden: results based on the Women's Health Initiative randomized controlled trial. Int J Technol Assess Health Care. 2005; 21:433-441. [PubMed: 16262965]

75. NICE. Osteoporosis—secondary prevention including strontium ranelate: Appraisal consultation document. 2008. www.nice.org.uk

76. Borgstrom F, Johnell O, Kanis JA, Oden A, Sykes D, Jonsson B. Cost effectiveness of raloxifene in the treatment of osteoporosis in Sweden: an economic evaluation based on the MORE study. Pharmacoeconomics. 2004; 22:1153-1165. [PubMed: 15612833] 


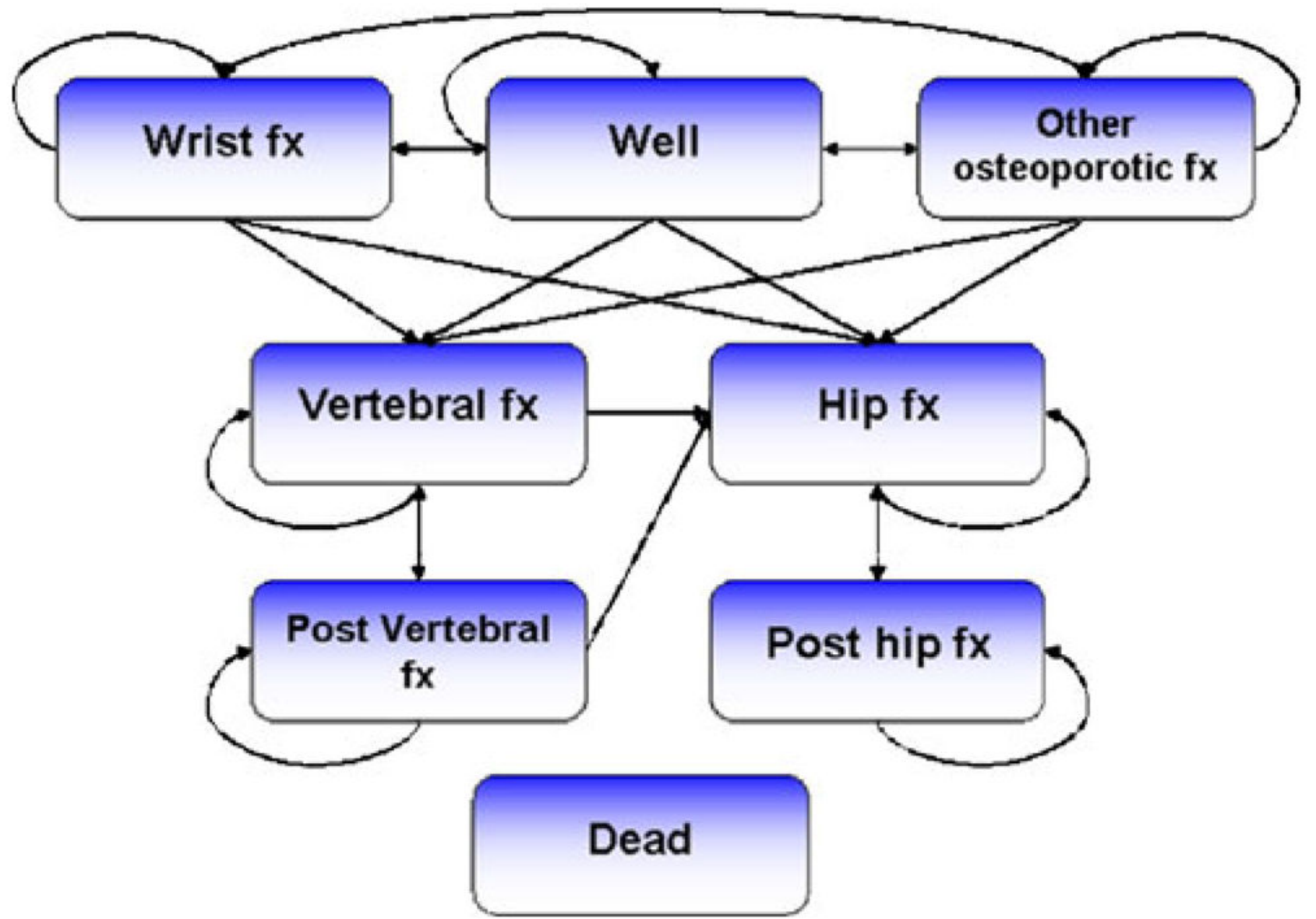

Fig. 1.

Structure of the denosumab Markov cohort model. Note: The health state "dead" is always accessible and arrows were excluded for simplification 


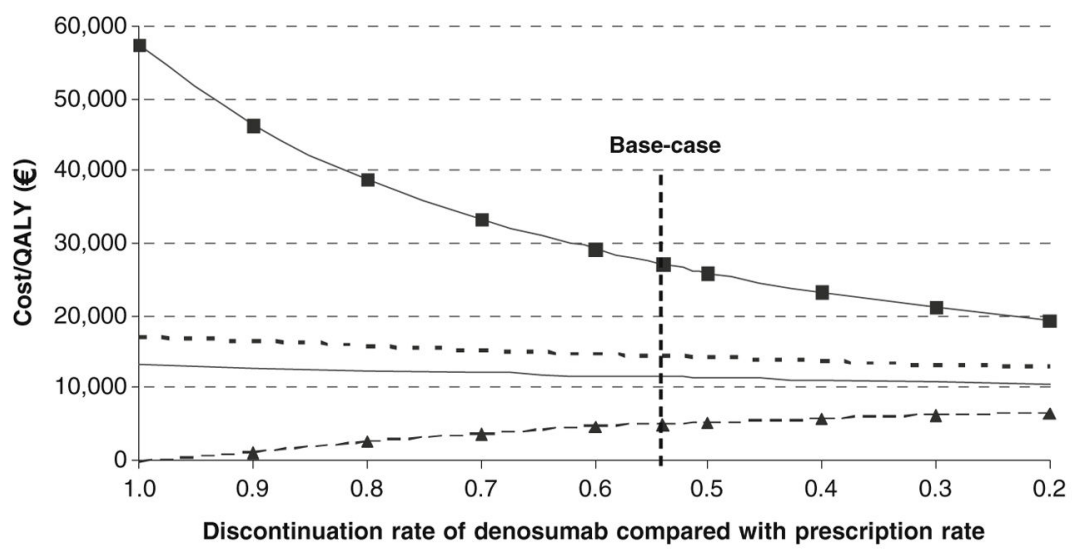

$$
\begin{array}{|l|l|}
\hline-\ldots-\text { denosumab vs. no treatment } \longrightarrow \text { denosumab vs alendronate } \\
\hline
\end{array}
$$

Fig. 2.

Effect of variations in persistence of denosumab on incremental cost-effectiveness of denosumab versus comparators for the base-case population 


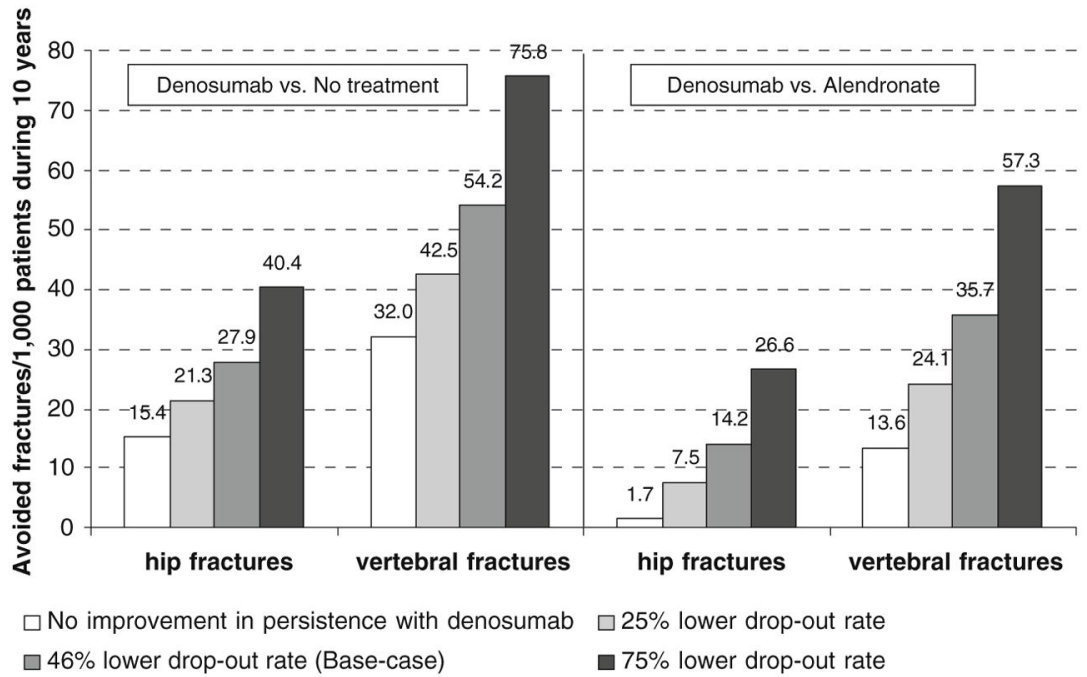

Fig. 3.

Number of avoided fracture per 1,000 patients from the base-case population according to differences in persistence between denosumab and alendronate 

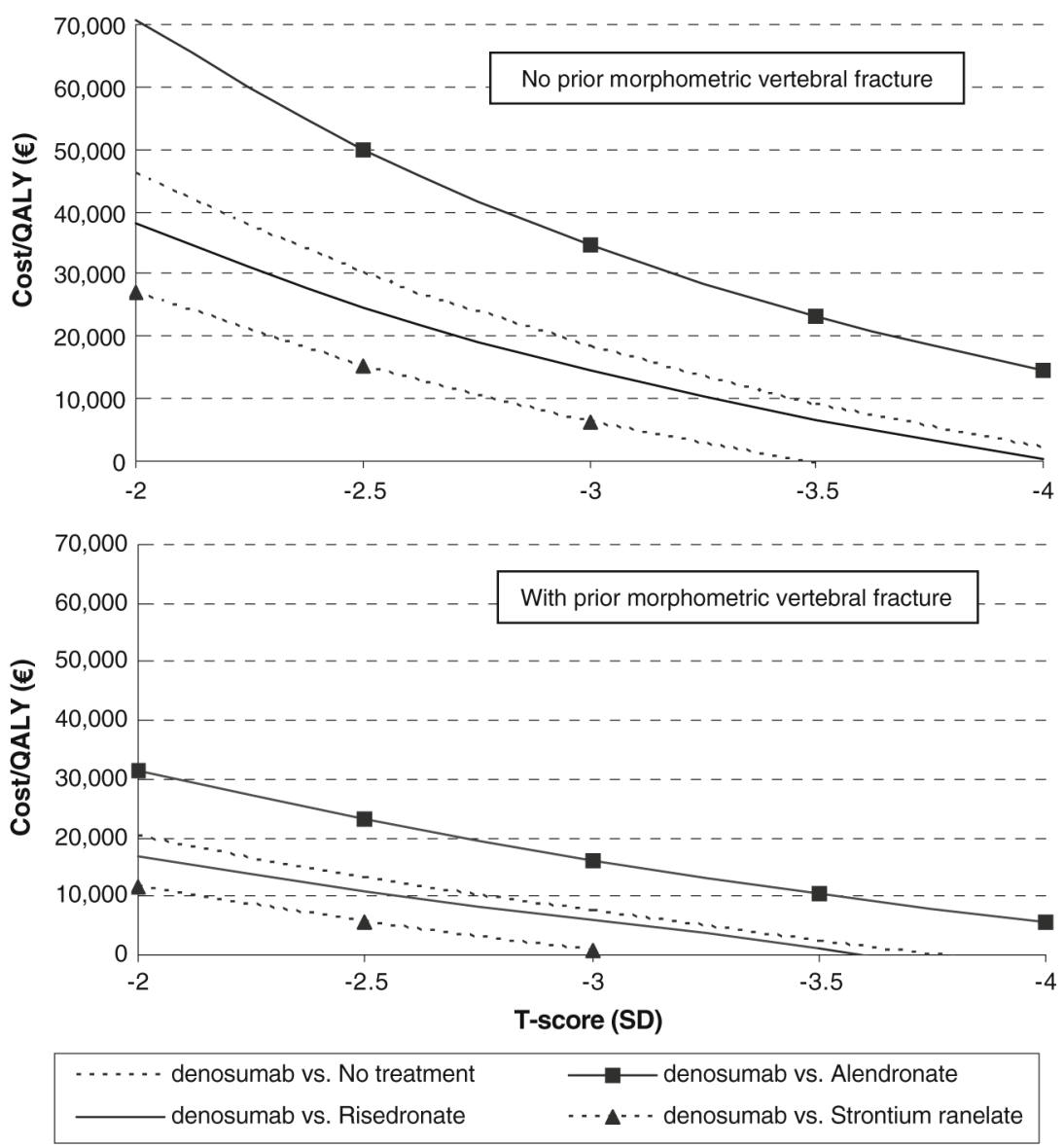

Fig. 4.

Cost-effectiveness (cost/QALY gained) as a function of T-score and prior fracture in 71year-old women 


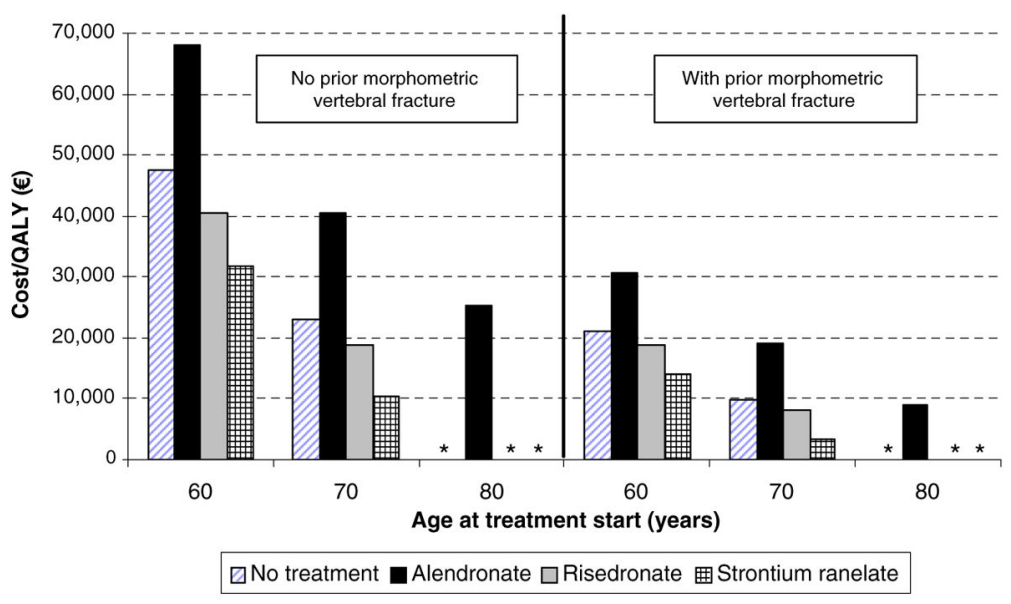

Fig. 5.

The effect of age at start of treatment with or without a prior fracture (T-score at or below $-2.5 \mathrm{SD}$ ) on the cost-effectiveness of denosumab vs. comparators. Asterisk (*), Denosumab is cost saving

* Denosumab is cost-saving 


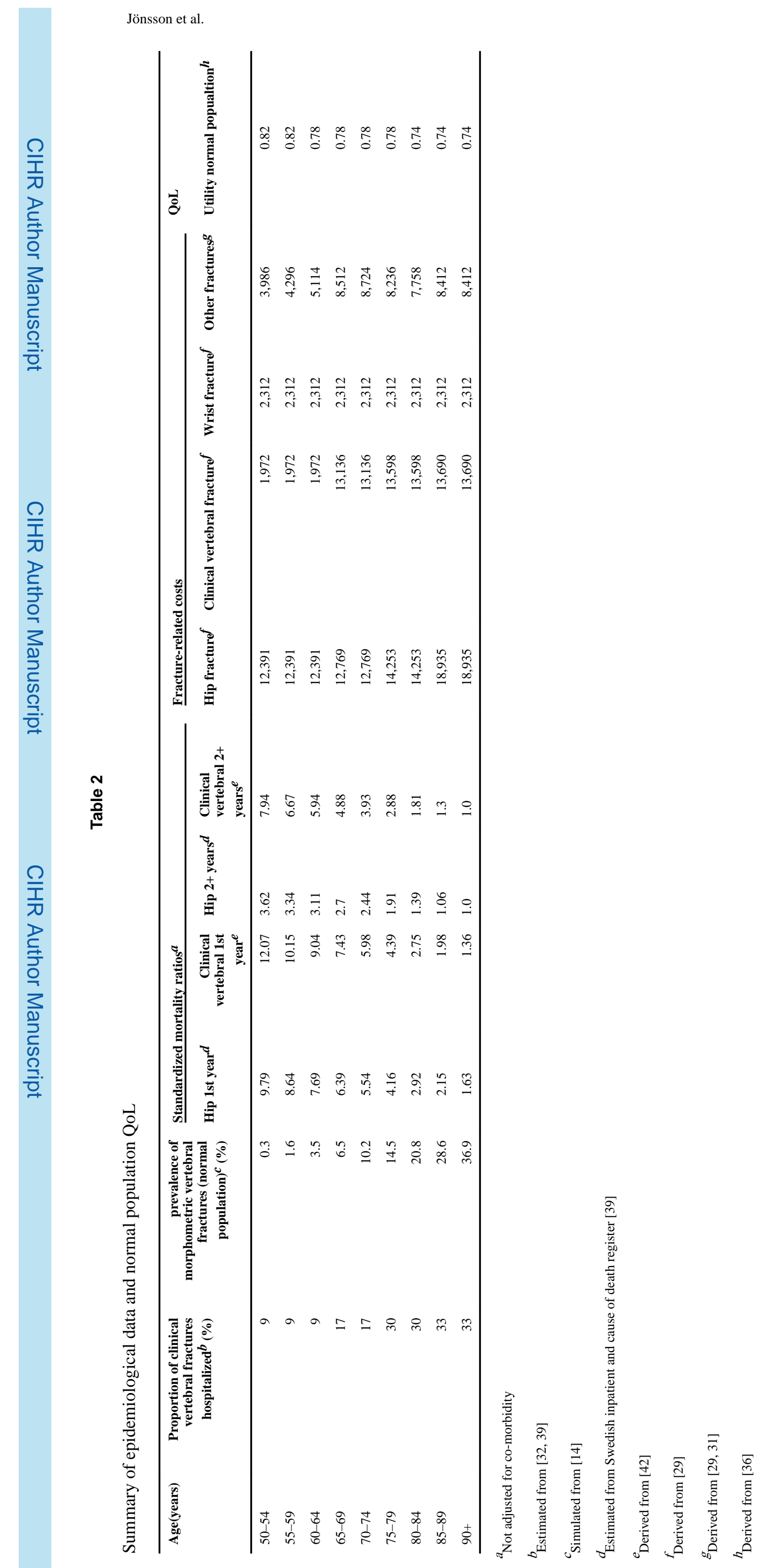


Table 4

Base-case analysis for incremental cost-effectiveness (cost per life year and QALY gained)

\begin{tabular}{lllll}
\hline & $\begin{array}{l}\text { Denosumab vs. no } \\
\text { treatment }\end{array}$ & $\begin{array}{l}\text { Denosumab vs. } \\
\text { generic } \\
\text { alendronate }\end{array}$ & Denosumab vs. risedronate & $\begin{array}{l}\text { Denosumab vs. } \\
\text { strontium } \\
\text { ranelate }\end{array}$ \\
\hline Costs/patient (€) & $-1,762$ & -937 & $-1,132$ & $-1,339$ \\
Morbidity cost difference & 1,868 & 1,530 & 1,055 & 939 \\
Treatment cost difference ${ }^{a}$ & 936 & 562 & 643 & 658 \\
Cost in added life years & 1,042 & 1,155 & 565 & 258 \\
Total cost difference & & & -23 \\
Avoided fractures during 10 years/1,000 patients & -28 & -14 & -19 & -37 \\
Hip fractures & -54 & -36 & -39 & 44 \\
Vertebral fractures & 36 & 71 & 54 & 27 \\
NNT to avoid one hip fracture & 18 & 28 & 26 & 0.0409 \\
NNT to avoid one vertebral fracture & & & & 0.0281 \\
QALYs and life years per patient & 0.0582 & 0.0349 & 0.0400 & 0.0514 \\
Life years gained (undiscounted) & 0.0401 & 0.0240 & 0.0274 & 9,161 \\
Life years gained (discounted) & 0.0721 & 0.0426 & 0.0490 & Cost saving \\
QALYs gained & 25,980 & 48,226 & 20,592 & 5,015 \\
Cost/life year gained & 1,476 & 13,907 & Cost saving & \\
Cost per QALY gained (excluding & 14,458 & 27,090 & 11,545 & \\
CIALY) & & & & \\
Cost per QALY gained & & & & \\
\hline
\end{tabular}

Women aged 71 years with a T-score at or below $-2.5 \mathrm{SD}$ and $34 \%$ prevalence of prior vertebral fracture $N N T$ number needed to treat

${ }^{a}$ Including monitoring costs 


\section{Table 5}

Other sensitivity analyses (€/QALY)

\begin{tabular}{llccl}
\hline Scenario & $\begin{array}{l}\text { Denosumab vs. } \\
\text { no treatment }\end{array}$ & $\begin{array}{c}\text { Denosumab vs. } \\
\text { generic } \\
\text { alendronate }\end{array}$ & $\begin{array}{c}\text { Denosumab vs. risedronate } \\
\text { Denosumab vs. } \\
\text { strontium } \\
\text { ranelate }\end{array}$ \\
\hline Base case $^{a}$ & 14,458 & 27,090 & 11,545 & 5,015 \\
Discount rates (5\%) & 15,453 & 29,617 & 11,979 & 4,923 \\
Discount rates (0\%) & 13,638 & 24,135 & 11,501 & 5,707 \\
1 year DAPS persistence & 15,937 & 35,114 & 12,983 & 4,313 \\
Perfect persistence for all treatments & 11,936 & 66,604 & 10,750 & Cost saving \\
Denosumab maximum offset time 2 years & 19,937 & 40,531 & 19,547 & 11,237 \\
All treatments maximum offset time 2 years & 19,937 & 34,920 & 16,953 & 9,896 \\
10-year modeling horizon & 13,833 & 32,993 & 8,752 & 10 \\
GIAEs ${ }_{\text {for alendronate/risedronate }}$ & - & 26,595 & 11236 & - \\
Disutility from fractures decreased by 10\% & 16,362 & 30,633 & 13,057 & 5,685 \\
20\% of excess mortality attributable to fractures & 10,951 & 25,340 & 7,587 & 228 \\
10 year treatment duration & 14,375 & 28,145 & 11,532 & 4,569 \\
Mortality after hip and vertebral fractures 3 years & 11,675 & 25,504 & 8,347 & 1,276 \\
Mortality after hip and vertebral fractures 5 years & 13,459 & 26,485 & 10,387 & 3,675 \\
\hline
\end{tabular}

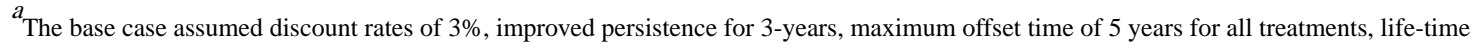
horizon, no adverse events for any treatment, 5-year maximum treatment duration, 8 years of increased post-fracture mortality after hip and vertebral fractures

$b_{\text {Gastrointestinal adverse events }}$ 